The Effects of School Policing in School on Victimization, Violence, Fear of Crime: Focusing on Korean Youth

Sungil Han

The University of Texas at Dallas

Nadine M. Connell

Griffith University 


\title{
The Effects of School Police Officers on Victimization, Delinquency, and Fear of Crime: Focusing on Korean Youth
}

\begin{abstract}
As a response to rising concerns about school violence, the Korean National Police Agency began recruiting specialized police officers, called Korean School Police Officers (KSPOs), in hopes that they would reduce in school behavioral and delinquency problems. The current study provides insight into the effects of crime prevention activities in Korean schools, using the 2014 Korean Youth Victimization Survey to advance the knowledge about the role of the KSPOs and their potential impact on delinquency reduction. Results indicate that the presence of KSPOs did not have any significant association with criminal victimization or fear of victimization. In some cases, the presence of KSPOs is associated with higher property crime by students. Implications of these findings for understanding KSPOs and their roles in preventing school crime and improving school environments are discussed. In addition, we discuss how lessons learned from the U.S. may influence future advancements in KSPO approaches and vice versa.
\end{abstract}

Keywords: school resource officers; school policing; juvenile delinquency; fear of crime 


\section{Introduction}

As a response to rising concerns about school violence, school administrations and police departments have implemented a variety of strategies to enhance school safety (Brown, 2006). As a result, numerous crime prevention programs, from highlighting educational functions to enhancing the physical security of the school environment, have been introduced in recent years (Gottfredson, Wilson, \& Najaka, 2002). One increasingly common intervention has become the presence of police officers in school, otherwise known as School Resource Officers (SRO), especially as increased funds have provided the opportunity for school and police partnerships (Devlin \& Gottfredson, 2018).

In South Korea, school crime has become a serious social problem, especially in the form of bullying; after several students committed suicide due to problems with peers, school administrators have begun to actively adopt various intervention and prevention strategies, including school policing (Hong, Lee, Lee, Lee, \& Garbarino, 2014; Kim, 2015). Similar to schools in the U.S., but customizing to Korean culture, the Korean National Police Agency began recruiting specialized police officers who have a degree in counseling or youth education in hopes that they would more successfully help deal with school problems in 2012 (Kim \& Hwang, 2016). However, in contrast to trends in the U.S., only a handful of studies have attempted to evaluate the effectiveness of this program. Most studies to date, primarily appearing in Korean language journals, discuss the purpose and process of program implementation from a conceptual perspective but have refrained from outcome evaluation.

In this respect, the current study provides insight into the effects of crime prevention activities in Korean schools, focusing on KSPOs for two reasons. First, this study attempts to offer empirical evidence of the impact of school policing strategies that are similar to various 
activities in the U.S., while considering the unique Korean school context. The data were retrieved from the Korean Youth Victimization Survey (2014), which measured various aspects of school environments and crime victimization experiences of Korean students. Thus, this study introduces school crime prevention initiatives launched in a foreign county and subsequent effects on school safety. For example, KSPOs mainly focus on counseling roles, such as quick response to school crime reports and proper care of victims. Second, this study examines how the presence of KSPOs in schools affects various school safety-related indicators, such as school crime victimization and fear in schools. This allows us to better understand the effects of school policing strategies on several aspects of the school environment, which will help inform school policing strategies in Korea and beyond.

\section{Background}

School crime prevention activities have been developed based upon various considerations, including characteristics of the school, individual-level experiences, peer group experiences, and criminogenic commodities (Gottfredson et al., 2002). Among the numerous crime prevention programs, school resource officer programs have been welcomed due to expected reductions in school crime and violence.

Despite the growing popularity of SROs in the U.S., the role and responsibilities of SROs have not been clearly defined (Devlin \& Gottfredson, 2018). The major duties of SROs, in general, are to ensure school safety through various law enforcement-oriented activities, to solve delinquency problems in schools, and to offer educational programs for students, such as drug use prevention (Finn \& McDevitt, 2005; Finn, Shively, McDevitt, Lassiter, \& Rich, 2005; James \& Mccallion, 2013; Na \& Gottfredson, 2013; Zhang, 2018). The National Association of SROs stipulates that the roles of SROs consist of a triad model, comprising three major components: 
law enforcement, education, and informal counseling roles (Canady, James, \& Nease, 2012).

Police officers with arrest authority are expected to play a traditional and typical law

enforcement role, with activities such as patrolling (Bracy, 2011; Coon \& Travis, 2012). The

education duties encompass various law and crime related classes to promote positive behavior among students, with topics including knowledge of criminal justice system, substance use/abuse

prevention, and conflict resolution (Finn \& McDevitt, 2005; Weiler \& Cray, 2011). Lastly, as an officer who works for students, SROs are also expected to build bonds of trust with students, staff, and parents in order to assist them with law-related matters (Canady et al., 2012; Girouard, 2001).

\section{Effectiveness of SRO in reducing crime and improving the school environment}

To date, most of our knowledge about how the presence of SROs affect school environments comes from the U.S. experiences. While they may not generalize to the South Korean experience, they offer a starting point for understanding the direction of hypotheses and engaging in empirical research with new SRO programs. As such, it is briefly reviewed here.

Crime in school. Advocates of SRO programs believe that SROs can be effective in reducing school violence by increasing potential deterrence and surveillance as well as building relationships with students, who will then be willing to cooperate with SROs (Kipper, 1996; McDevitt \& Panniello, 2005). However, evidence on the effectiveness of these programs has been inconsistent. Some studies have suggested that SRO programs reduce violence in schools (Carroll, Ben-Zadok, \& McCue, 2010; Johnson, 1999; Maskaly, Donner, Lanterman, \& Jennings, 2011). For instance, Johnson (1999) analyzed data from nine high schools and eighteen middle schools, revealing that overall school suspensions gradually decreased in both middle and high schools with the placement of police officers. 
In contrast, other studies have reported no meaningful difference in violence between schools with SROs and without SROs (Barnes, 2008; Brady, Balmer, \& Phenix, 2007); some even report increased violence at schools with SROs (Jackson, 2002; Na \& Gottfredson, 2013). In particular, Barnes (2008) compared the crime rate of schools with SROs with their counterparts and suggested that SROs being placed at schools showed little or no meaningful impact on North Carolina public schools. Meanwhile, Na and Gottfredson (2013) employed a longitudinal sample of 480 schools to investigate violence reduction and found that the increased use of SROs had a positive effect on crime rates, indicating that schools adding more SROs are likely to report more crime.

Recently, concerns over the collateral consequences of SRO programs in the U.S. have emerged through research on the school to prison pipeline. This line of inquiry suggests that as school administrations begin to depend on SROs for behavioral issues that were previously handled by teachers or other staff, such as routine disorderly conduct, more arrests are an inevitable consequence, which leads to the increasing involvement of students in the criminal justice system (Brown, 2006; Devlin \& Gottfredson, 2018; Jennings et al., 2011; Na \& Gottfredson, 2013; Theriot, 2009). For example, Theriot (2009) evaluated rates of arrests and charges per one hundred students in twenty-eight schools in a southeastern U.S. county and suggested that disorderly behavior arrests were consistently higher in schools with SROs while arrest rates for other types of misbehavior or criminal behavior were not different. These issues underscore the necessity of understanding the day to day duties of SROs in order to better determine where they are helping and where they are hurting. Additionally, this research is all within an American context; assumptions about these outcomes in other cultures need to be tested empirically. 
Fear of Crime. Advocates of SROs argue that stationing uniformed law enforcement officers at schools enhances student feeling of safety (McDevitt \& Panniello, 2005). However, only a few studies have investigated the effects of SROs on student fear of crime or perceptions of safety (Bosworth, Ford, \& Hernandez, 2011; Brown \& Benedict, 2006; McDevitt \& Panniello, 2005; Theriot \& Orme, 2016). Generally, students have reported less fear and more sense of safety in schools with SROs (Brown, 2005; McDevitt \& Panniello, 2005; Theriot \& Orme, 2016). For example, Theriot and Orme (2016) revealed that students generally have better feelings of safety when they possess positive attitudes toward SROs and their activities. When students have favorable attitudes toward SROs, they feel safer in school and more comfortable in reporting crime and victimization. This has been seen not only with SROs but with security measures in general (Connell, 2019). In contrast, Schreck and Miller (2003) postulated that the presence of SROs in schools could increase fear of crime, since SROs may prime students to think about things like crime and victimization and many create a sense of fear not in line with reality. For example, the results of a study examining the association between school security and students' fear of crime suggested that school safety measures, such as locked doors and supervises hallways, were related to higher fear of crime among 6,427 students in grades 6 through 12 (Schreck \& Miller, 2003). In sum, many studies reported the positive effects of SROs on students' feeling of safety. However, the feeling of safety is usually dependent upon or at least conditioned by the students' perception that police are there for their protection and not for their oppression.

\section{SROs in South Korea}

The current Korean School Policing system was established in 2012 with a declaration of "School Police Officer Plan" by the National Police Department, highlighting three unique 
components: certified officers, mixed roles of police officers, and a technology friendly system. One of the special components of school police program in South Korea is to recruit police officers (so-called certified school police officers) who have a university degree in youth development, education, counseling, and psychology. According to the National Police Department, 1,075 police officers were stationed at schools in 2016 and 243 certified officers with university degrees were newly employed as a result of this imitative (Kim \& Hwang. 2016). Not all police officers who are stationed at schools currently satisfy the new requirement, but the police department plans to expand going forward (Korean National Police, 2015). Once certified police officers get recruited, they receive an additional 35 hours of youth-related training that comprises various subjects, such as how to deal with school crime, understanding of youth punishment, running diversion programs and crime prevention education, recording testimony from youth, and juvenile justice system procedures (Kim \& Hwang. 2016). After completing additional training classes, officers can be stationed at any level of school (elementary, middle, or high school).

The second characteristic of KSPOs is to focus on the mixed roles of school police officers, which includes security as well as community building rather than traditional police work, such as responding to crime and deterring students with authority. The National Police Department stipulates that the roles of KSPOs entail building cooperation within schools to share information on school crime, giving classes for crime prevention, participating in school crime committee meetings, and responding to reports of school crime (Kim, 2015). Recent findings from a comparative study on the perceptions of school police officers between the U.S and South Korea indicated that school police officers in South Korea spend more than half of their days on 
counseling and educating activities, compared to American SROs who spend approximately sixty percent of their time on law enforcement activities (Lee, 2016).

The last unique feature of the National Police Department is using high-tech technologies such as a mobile application for school crime reporting, called "117 Chat." This student serving application consists of crime reporting options and contact information for school police officers, along with other resources that the victim may need (Korean National Police, 2015). This application is designed to provide a more student-friendly way to report their victimization or to seek help from related agencies. According to the most recent report of the National Police Department, 71,985 cases of school victimization and requests for counseling were reported to police through the 117 hotline and 117 chat application (Korean National Police, 2018).

As a result of considerable investment in the KSPOs program, a recent survey of teachers revealed that $69 \%$ of responding teachers support KSPOs and $64.6 \%$ answered that KSPOs have been effective in reducing school crime (Kim, 2015) ${ }^{1}$. The National Police Department also reported that school crime victimization recorded a dramatic decline since the school police system has been introduced (Korean National Police, 2015).

\section{Current Study}

The purpose of this study is to introduce the Korean School Resource Officer program to the research community and examine its effects on various facets of school safety. Based on previous literature and the goals of the KSPOs program, this study examines the following hypotheses. In particular, KSPOs are expected to have negative associations with victimization, violence, and fear.

\footnotetext{
${ }^{1}$ However, this is lower than the support for SROs in the U.S. One study revealed that more than $90 \%$ of high and middle school principals supported SRO and $88 \%$ of school administrators answered that crime decreased in schools after SROs were assigned in Kentucky (May, Fessel, \& Means, 2004).
} 
a. The presence of KSPOs is negatively associated with in-school victimization.

b. The presence of KSPOs is negatively associated with in-school violence.

c. The presence of KSPOs is negatively associated with fear of school crime.

\section{Method}

\section{Data}

For this study, the Korean Youth Victimization Survey (Hong \& Yeon, 2014a) from 2014 is analyzed. The Korean Institute of Criminology conducted this survey to study a variety of youth related concerns, including victimization status, victim characteristics, fear of crime, and the effects of victimization. A national multi-stage stratified cluster sampling technique was employed in order to obtain a nationally representative sample of schools, resulting in a total of 158 schools participating in the research ${ }^{2}$. In each selected school, two classes were sampled and students in those classes answered the survey about offending and victimization experiences through an online portal designed to secure (Hong \& Yeon, 2014b). A total of 7,109 middle and high school students completed in the survey. While the cross-sectional data set does have limitations in explaining the causal relationship between variables, the nationally representative sample increases generalizability. The results of descriptive statistics in Table 1 show the characteristics of the sample population.

$* * * * *$ Table 1 Here $* * * * *$

Very few students reported they committed violent delinquent behaviors. For all three types of delinquent behaviors including, violent, property, and general bullying, only $1 \%$ of students report participation. Two percent of students said that they experienced at least one type

\footnotetext{
${ }^{2}$ A total of 1,546 schools were contacted for the survey and $158(10.2 \%)$ schools participated in the study.
} 
of violent victimization in the prior year. Compared to violent victimization, students report more property crime victimization in a prior year. Approximately $11 \%$ of students reported property crime victimization. Similar to violent crime, $3 \%$ of students answered that they had been bullied during the prior year. Additionally, more than half of the students attend school with KSPOs. Demographically, $47 \%$ of respondents are male and the average age is 16.5 years old. ${ }^{3}$

\section{Measurement}

Dependent variables. In keeping with previous literature, we examine several dependent variables in order to assess the effect of KSPOs on school environment. They are grouped into self-reported delinquency, victimization experiences, and fear of crime. Each sub-category for behavior, victimization, and fear is broken down according to the type of criminal behavior: violent, property, and bullying.

Delinquency: Students were asked about their participation in delinquent behaviors in the last year. Violent behavior consists of assault, robbery, and threatening with force. Students who responded yes to any of these behaviors are coded as Yes (Yes=1; 1\%). Property crime consists of burglary, fraud, and stealing. As with violent behavior, this is a dichotomous measure with students reporting participation in any of these behaviors coded as yes (Yes=1; 1\%). Similarly, students who reported having participated in isolating peers or forcing others to do an errand are coded as participating in bullying perpetration $(\mathrm{Yes}=1 ; 1 \%)^{4}$.

Victimization: A similar strategy was employed to measure crime victimization experiences. Students were asked about their experiences with assault, robbery, and threats by

\footnotetext{
${ }^{3}$ The dataset did not include missing data. We assume as a result that skipping questions was not allowed. We recognize that this means that some respondents could have felt obligated to fill out questions in a positive manner, but we do not believe any effects would be more than what normally occurs with regards to social desirability considerations.

${ }^{4}$ Bullying embraces a wide range of behavior that brings negative consequences to victims. The two items used here were included in the survey to measure bullying in school because these two types of bullying are considered the most common in South Korea (Hong \& Yeon, 2014b).
} 
force. A single dummy indicator was created to represent the violent victimization of students if they answered yes to any question (Yes=1;2\%). Students were also asked about property crime victimization; if a student reported being the victim of burglary, fraud, or theft, they are coded as yes (Yes $=1 ; 11 \%)$. Two items were used to measure bullying victimization; students asked whether they experienced being isolated by other students or being forced to do errand. If respondents experienced at least one type of bullying victimization, they are recoded as yes (Yes=1;3\%).

Fear of Crime: In contrast to the other crime-related dependent variables, items used to capture student fear of crime were measured in five-point Likert scales; these are divided into fear of violence, fear of property crime, and fear of being bullied. For violent crime, students were asked whether they were fearful of assault, robbery, and threats by force. Each item is measured on a five-point scale ( $1=$ Not at All to $5=$ Very Much; Mean= $5.73, \mathrm{SD}=2.99)$. Principal Component Analysis (PCA) indicated that the three items explain the variance of the indicator with an acceptable factor loading value (Eigenvalue $=2.79$, Factor Loading $>.93$, Cronbach's alpha $=.96$ ). These three items were combined to form a summative index. Similarly, fear of property crime is measured by fear of burglary, fraud, and theft $(1=$ Not at All to $5=$ Very Much; Mean= $6.17, \mathrm{SD}=3.11)$. The PCA results indicated that the measure met traditional levels of reliability (Eigenvalue $=2.62$, Factor Loading $>.87$, Cronbach's alpha $=.93$ ) and a summative index for fear of property crime was created. The two items included in the fear of bullying index are fear of being excluded by peers and fear of being forced to do errand (1=Not at All to 5=Very Much; Mean 3.93, $\mathrm{SD}=2.13)$.

\section{Control variables}


Other Prevention. Some schools have also introduced additional school crime prevention programs, often focusing on peer relationship, teacher involvement, and parent involvement in South Korea (Hong et al., 2014). For example, the program Friends was launched to teach students about the importance of friendship and help improve peer relationships by focusing on bullying prevention in schools. This study controls for the presence of other school-based prevention programs in order to separate out the effects of KSPOs from the effects of other types of programming. Students were asked if they had participated in any school crime prevention programs or had students received mail regarding school crime prevention; responses were combined to represent the school crime prevention program which indicates higher values mean students experience more school crime prevention programs in the schools. (Mean=1.83, $\mathrm{SD}=$ 0.51; Eigenvalue $=1.84$, Factor Loading $>.88$, Cronbach's alpha $=.92$ ).

School Climate: Two variables are employed to capture school climate; disorder and students' attachment to teachers. Three items are utilized to measure the social and physical disorder in schools. Students are asked whether there were many delinquent students in their school, many criminal incidents such as robbery, stealing, and assault, and whether there are many dark and unmanaged places in their schools. These items are measured in four-point Likert scale options $(1=$ Not at All to $4=$ Very much; Mean $=5.02, \mathrm{SD}=1.85)$. PCA analysis suggests acceptable factor loading values (Eigenvalue $=2.08$, Factor Loading $>.67$, Cronbach's alpha $=.78$ ), and three items were combined to create a summative scale, with higher value indicating more disorder. Similarly, attachment to teachers is measured by three items; items asked whether students perceived that they could talk to their teachers about their worries, their teachers usually show them love, and they want to be like their teachers. Respondents answered on a four-point 
Likert scale, with higher value indicative of more attachment to teachers (Mean $=7.44, \mathrm{SD}$ $=2.37$; Eigenvalue $=2.41$, Factor Loading $>.80$, Cronbach's alpha $=.88$.

Demographics: Additionally, demographic characteristics of students are captured; gender and age. Gender is measured as dichotomous (Male $=1 ; 47 \%$ ) while age is captured by a continuous variable $($ Mean $=16.52, \mathrm{SD}=1.13)$.

\section{Analytic Strategy}

We undertake several analyses to approximate how the presence of KSPOs affects student delinquent behavior, victimization, and fear. First, simple mean comparison analyses are utilized to examine general differences in school safety outcomes between schools with KSPOs and without KSPOs. Second, in order to isolate the effects of KSPOs and consider other confounding effects, logistic regression analyses are estimated for the dichotomous delinquency and victimization outcomes. Because these events are very rare in this sample (fewer than $5 \%$ of respondents), there is concern about bias with estimates (as the probability of rare events is commonly underestimated); to correct for this, the rare events logistic analysis is considered as an alternative (King \& Zeng, 2001) since this analysis technique minimizes this bias (Tomz, King, \& Zeng, 2003). Thus, the rare events logistic analysis is operated to examine the effects of KSROs for offending and victimization while ordinary least squares regressions are estimated for the continuous nature outcomes of fear. Additionally, dependent variables are highly correlated to each other. For example, victimization experience is one of the more powerful predictors of higher levels of fear of crime (see Hale, 1996). Similarly, the combination of being victimized and also participating in violent behavior is commonly observed among juveniles. Thus, to account for effects of possible confounding variables, this study also includes victimization (fear of crime and delinquency model) and delinquency (victimization model) variables in the model. 


\section{Results}

Table 1 shows the results of mean comparison analyses between schools with KSPOs and without KSPOs. While students in schools with KSPOs reported fewer victimization experiences compared to students in schools without KSPOs, these differences were not significant. A similar trend is evident for violent delinquency and bullying, but students in schools with KSPOs reported higher levels of property related delinquency $(p<.05)$; which significant, the difference in magnitude is small. More meaningful, however, is the fact that students in schools with KSPOs are significantly less fearful of two types of victimization (property, $p<.01$; bullying, $p<.01)$. Students in schools with KSPOs reported, in general, less victimization, less violence, and less fear. We now turn to the regression analyses for further insight into this relationship.

Table 2 shows the results of adjusted logistic regression for delinquency behaviors and victimization. For the results of the logistic regression analysis, odds ratios (OR) are presented along with coefficient values to make the interpretation of the results easier. The OR indicates the increase/decrease in the chance of event being happened. The presence of KSPOs is associated with a higher chance of a student reporting having committed some type of delinquent property act $(\mathrm{OR}=2.42, p<.05)$. Students enrolled in schools with KSPO have 2.4 times higher odds of committing a delinquent property act than those enrolled in schools without a KSPO presence. However, there are no statistically significant relationships between the presence of KSPOs and self-reported violent delinquency or bullying. Of notable interest is the fact that having a different school crime prevention program (other than KSOPs) does not seem to be related to any of the delinquency outcomes. As expected, an increase in levels of school disorder is positively related to a higher likelihood that students report more violent delinquency $(\mathrm{OR}=1.16, p<.05)$ and bullying $(\mathrm{OR}=1.15, p<.05)$. Furthermore, students who hold higher levels 
of attachment to teachers are less likely to commit violent delinquency $(\mathrm{OR}=0.87, p<.05)$. Males have higher odds of reporting participation in both violent $(\mathrm{OR}=4.65, p<.01)$ and property $(\mathrm{OR}=2.58, p<.01)$ delinquency when compared to females; there are no gender effects evident for bullying. Older students, however, report lower odds of bullying $(\mathrm{OR}=0.69, p<.01)$ when compared to their younger peers. Self-reported victimization shows significant associations with all three types of delinquency (violent delinquency $(\mathrm{OR}=4.48, p<.01)$, property delinquency $(\mathrm{OR}=5.07, p<.01)$, and bullying $(\mathrm{OR}=4.05, p<.01))$.

Looking at the results for victimization, the presence of KSPOs is not associated with any of the three types of victimization. However, the presence of school crime prevention programs is significantly associated with both violent $(\mathrm{OR}=0.73, p<.05)$ and property $(\mathrm{OR}=1.25, p<.01)$ victimization experiences. Interestingly, students in schools with school crime prevention programs have lower odds of being violently victimized but higher odds of property crime victimization. Also, perceived levels of disorder play an important role in explaining various types of victimization. Disorder presents strong associations with a higher likelihood of reported victimization (Violent; $\mathrm{OR}=1.42, p<.01$, Property; $\mathrm{OR}=1.21, p<.01$, Bullying; $\mathrm{OR}=1.31, p<.01$ ). Male students report higher chance of violent $(\mathrm{OR}=1.68, p<.01)$ but lower odds of bullying victimization $(\mathrm{OR}=0.68, p<.01)$. These results are consistent with previous research that finds that male students are more likely to be victimized than their female counterparts, in part due to more risky lifestyles (Henson, Wilcox, Reyns, \& Cullen, 2010; Jensen \& Brownfield, 1986). However, male students reported lower odds of bullying victimization compared to female students. Age is also significantly associated with violent victimization $(\mathrm{OR}=0.75, p<.01)$ and bullying $(\mathrm{OR}=0.82, p<.01)$ experiences. As students mature, they report lower odds of these experiences. As a control variable, delinquency is also significantly associated with 
victimization. Students who engage in delinquent behavior report higher odds of victimization experiences as well (violent victimization; $\mathrm{OR}=3.58, p<.01$, property victimization; $\mathrm{OR}=2.65$, $p<.01$, bullying victimization; $\mathrm{OR}=2.14, p<.01)$.

In the U.S. context, reducing fear of crime is a goal of SROs in school, with some evidence to support this outcome (Brown, 2005; McDevitt \& Panniello, 2005; Theriot \& Orme, 2016). However, in these data, the KSPOs are not associated with lower levels of fear of crime. Neither the presence of KSPOs nor prevention programs are associated with fear of crime for the three outcomes. Meanwhile, disorder has a significant association with fear of violent $(b=.47$, $p<.01)$ and property $(b=.49, p<.01)$ crimes as well as bullying $(b=.34, p<.01)$. Attachment to teachers has a negative relationship with fear property crime $(b=-.03, p<.05)$. Consistent with general findings of fear of crime, male students report less fear of crime than their female counterparts, and this trend is observed for all types of crime (Violent, $b=-.90, p<.01$; Property, $b=-.91, p<.01$; Bullying, $b=-.77, p<.01)$. Victimization experiences show positive and significant associations with fear of crime. Students who had experienced victimization report higher levels of fear for violent crime $(b=.37, p<.01)$, property crime $(b=.83, p<.01)$, and bullying $(b=.57$, $p<.01)$.

$* * * * *$ Table 3 Here $* * * * *$

\section{Discussion and Conclusion}

This study examined the effects of school resource officers in South Korea on school safety outcomes while introducing the unique components of Korean school police officers (KSPO). As school crime, especially bullying victimization, became a serious social issue in Korea, the National Police agency launched the Korean customized school police officer program, highlighting the importance of counseling and education. Consequently, the findings of 
the study add a unique contribution to discussions of the effects of the presence of police officers at schools and the roles of police in school.

While we hypothesized that the presence of KSPOs would be associated with lower levels of school delinquency and fear measures, we find only limited supportive evidence. For example, the presence of KSPOs was not related to violent, property, or bullying victimization experiences. These results point to the need for more information about the role of KSPOs, especially in light of the fact that they are a recent initiative. These results do not reach the point of calling the program ineffective, as research in the United States has pointed to the importance of time of implementation; SROs may not be effective until they have been part of a school community for several years (Finn \& McDevitt, 2005). Given that KSPO program is a new intervention in Korea, the intended positive effects may need time to manifest. Also, students in schools with KSPOs had a higher probability of committing property delinquency. It is important to point out, however, that the data limited analysis of temporal order; it is possible that schools with more property crime would have been more likely to be assigned a school resource officer. Indeed, safety measures are generally adopted by schools in need of solutions to address those safety issues, something that cannot be teased out by these data (Jennings et al., 2012).

\section{Limitations and Directions for Future Research}

Although this study adds the understanding of the effects of police officers in schools as a result of the unique strategy and activities in South Korea, it also raises questions that future studies need to consider. First, the data only allow for the measurement of the presence of the school resource officer; as with U.S. studies, more nuanced information is lacking. That said, it appears that the KSPO program takes a more qualitatively different approach, with an emphasis on prevention and community policing ideas, than many U.S. SRO programs. Nonetheless, 
without information about how a school gets assigned a KSPO, it is not possible in these data to tease out whether the KSPO is a response to a crime and delinquency problem or is driving a crime/delinquency problem. As such, we are restricted to a general discussion of the effects of KSPOs on school safety outcomes. We also acknowledge that the lack of information about missing data limits our generalizability in other ways, as we do not know how different those schools that did participate are from those that did not participate.

Secondly, some of the outcomes of KSPO are measured by a restricted number or concept of items. For instance, bullying victimization and offending are measured with two items asking whether respondents were isolated or forced to run errands for older peers. We know that bullying consists of a wide range of behaviors and the focus here is limited. But while these two may not be as commonly measured in North American or European contexts, they are behaviors deemed important by government and school officials in South Korea and thus, important targets of the behavioral interventions involved in the KSPO programs. We do recognize that it does create a limitation into the type of comparisons that can be made between countries and we hope that future studies will take our recommendation to include more behavioral outcomes to accurately evaluate the effects of the intervention. This is also important in light of the fact that much of the research on SROs focuses on more violent behavioral acts which may not truly encompass the types of lower stakes bullying interactions that students are more likely to encounter (e.g. Crawfod \& Burns, 2015; 2016).

Third, school characteristics, such as general academic performance, number of students, student characteristics, and being a public/private school may play an important role in determining the effects of KSPOs. Similar to schools in the U.S., middle and high schools in South Korea vary regarding size, composition of the student population, and location. Therefore, 
it is reasonable to assume school characteristics may influence how KSPOs go about their roles and be otherwise related to crime and victimization outcomes. We are conscious that some of this information is not available as it applies to the current dataset; for instance, school size and location were not released and there is no way to connect these findings to individual schools. This was a decision made at the level of the government agency, presumably for reasons for privacy, but we hope that the findings our of study offer the encouragement necessary to release more of these contextual descriptors for future research. One area that could not be examined here was the relationship between the school administration and the KSPOs, which research has pointed out as critical to the success of school policing programs (Finn et al., 2005; Johnson, 1999; Theriot, 2016). It is especially important in the Korean context, as one of the major components of KSPOs is to build bonds with students, teacher, and parents and to highlight educational and counseling functions. Also missing is the knowledge of how the KSPOs spend their time and what the implementation of general operational goals looks like. This is a common criticism of studies of school police officers in any context so we hope these findings serve as a platform for more nuanced data collection of officer activities.

Like many other social and government strategies for crime that are driven by a sense of urgency, SROs have been widely adopted and have become a popular crime control strategy; without the clear and scientific evidence on its efficacy; indeed, research on the school to prison pipeline points to the negative consequences of this approach (Devlin \& Gottfredson, 2018; Na \& Gottfredson, 2013; Theriot, 2009). Correspondingly, the Korean Police Department launched the Korean customized school police officer program and stationed police officers at schools across the nation without any scientific support for the program. Government officials have argued that there has been a decrease in school crime since the introduction of KSPOs (Korean 
National Police, 2015). However, the findings of the study indicate that such conclusions may be overstated. Also, the results regarding effects of the school climates point to the importance of managing the school environment to reduce delinquency, victimization, and fear. The KSPO program has a unique charter which may give them more control over such disorder issues, suggesting that there is still much to learn about the effects of school police officers, both in the U.S. and Korean contexts. As more countries adopt such school safety strategies, the importance of cultural context is highlighted, as is the need to better understand how school police officers fit into the broader school community. 


\section{References}

Barnes, L. M. (2008). Policing the schools: An evaluation of the North Carolina school resource officer program. Rutgers The State University of New Jersey-Newark.

Bosworth, K., Ford, L., \& Hernandaz, D. (2011). School climate factors contributing to student and faculty perceptions of safety in select Arizona schools. Journal of school health, 81(4), 194-201.

Bracy, N. L. (2011). Student perceptions of high-security school environments. Youth \& Society, 43(1), 365-395.

Brady, K. P., Balmer, S., \& Phenix, D. (2007). School-police partnership effectiveness in urban schools: An analysis of New York City's Impact Schools Initiative. Education and Urban Society, 39(4), 455-478.

Brown, B., \& Benedict, W. R. (2005). Classroom cops, what do the students think? A case study of student perceptions of school police and security officers conducted in a Hispanic community. International Journal of Police Science \& Management, 7(4), 264-285.

Brown, B. (2006). Understanding and assessing school police officers: A conceptual and methodological comment. Journal of Criminal Justice, 34(6), 591-604.

Canady, M., James, B., \& Nease, J. (2012). To protect and educate: The school resource officer and the prevention of violence in schools. Hoover, AL: National Association of School Resource Officers.

Carroll, J., Ben-Zadok, E., \& McCue, C. (2010). Evaluation of efficiency in crime control and crime prevention programs. American journal of criminal justice, 35(4), 219-235.

Connell, N.M. (2019). Fear of crime at school: Understanding student perceptions of safety as a function of historical context. Youth Violence and Juvenile Justice. 16(2): 124-136.

Coon, J. K., \& Travis III, L. F. (2012). The role of police in public schools: A comparison of principal and police reports of activities in schools. Police Practice and Research, 13(1), $15-30$.

Crawford, C., \& Burns, R. (2015). Preventing school violence: assessing armed guardians, school policy, and context. Policing: An International Journal of Police Strategies \& Management, 38(4), 631-647.

Crawford, C., \& Burns, R. (2016). Reducing school violence: Considering school characteristics and the impacts of law enforcement, school security, and environmental factors. Policing: An International Journal of Police Strategies \& Management, 39(3), 455-477.

Devlin, D. N., \& Gottfredson, D. C. (2018). The roles of police officers in schools: Effects on the 
recording and reporting of crime. Youth violence and juvenile justice, 16(2), 208-223.

Finn, P., \& McDevitt, J. (2005). National assessment of school resource officer programs: Final project report. Document Number 209273. US Department of Justice.

Finn, P., Shively, M., McDevitt, J., Lassiter, W., \& Rich, T. (2005). Comparison of program activities and lessons learned among 19 school resource officer (SRO) programs. Document Number 209272. US Department of Justice.

Fisher, B. W., \& Hennessy, E. A. (2016). School resource officers and exclusionary discipline in US high schools: A systematic review and meta-analysis. Adolescent Research Review, 1(3), 217-233.

Girouard, C. (2001). School resource officer training program. Washington, DC: US Department of Justice, Office of Justice Programs, Office of Juvenile Justice and Delinquency Prevention.

Gottfredson, D. C. (2017). Prevention research in schools: Past, present, and future. Criminology \& Public Policy, 16(1), 7-27.

Gottfredson, D. C., Wilson, D. B., \& Najaka, S. S. (2002). School-based crime prevention. Evidence-based crime prevention, 56, 164.

Hale, C. (1996). Fear of crime: A review of the literature. International review of Victimology, $4(2), 79-150$.

Henson, B., Wilcox, P., Reyns, B. W., \& Cullen, F. T. (2010). Gender, adolescent lifestyles, and violent victimization: Implications for routine activity theory. Victims \& Offenders, 5(4), 303-328.

Hong, J. S., Lee, C. H., Lee, J., Lee, N. Y., \& Garbarino, J. (2014). A review of bullying prevention and intervention in South Korean schools: An application of the socialecological framework. Child Psychiatry \& Human Development, 45(4), 433-442.

Hong, Y., \& Yeon, S. (2014a). Juvenile Victimization in Korea. Korean Institute of Criminology. Retrieved from http://hdl.handle.net/20.500.12236/22941.

Hong, Y., \& Yeon, S. (2014b). Juvenile Victimization in Korea. Seoul: Korean Institute of Criminology.

Jackson, A. (2002). Police-school resource officers' and students' perception of the police and offending. Policing: An International Journal of Police Strategies \& Management, 25(3), 631-650.

James, N., \& McCallion, G. (2013). School resource officers: Law enforcement officers in schools. Congressional Research Service, June, 26. 
Jensen, G. F., \& Brownfield, D. (1986). Gender, lifestyles, and victimization: Beyond routine activity. Violence and victims, $1(2), 85$.

Johnson, I. M. (1999). School violence: The effectiveness of a school resource officer program in a southern city. Journal of Criminal Justice, 27(2), 173-192.

Kim, Y. S. (2015). Achievements of the comprehensive measures of Korean Police for the elimination of school violence and counter strategies. The Journal of the Korea Contents Association, 15(4), 168-178. [Korean]

Kim, S.G. \& Hwang, J.S. (2016). The bright and dark sides of School Police Officers and the future direction. Jin Cheon, Korea: Korean Educational Development Institute. [Korean]

King, G., \& Zeng, L. (2001). Logistic regression in rare events data. Political analysis, 9(2), 137163.

Kipper, B. (1996). Law enforcements role in addressing school violence. Police Chief, 63, 26-27.

Korean National Police. (2015). Korean national police agency 2015 white paper. Seoul, Korea: Korean National Police Department.

Korean National Police. (2018). Korean national police agency 2018 white paper. Seoul, Korea: Korean National Police Department.

Lee, C.B. (2016). Comparative study about the perceptions of school resource officers in Korea and in the U.S.A.: An application of mixed methods. Korean Criminal Psychology Review, 12(1), 167-188. [Korean]

Maskaly, J., Donner, C. M., Lanterman, J., \& Jennings, W. G. (2011). On the association between SROs, private security guards, use-of-force capabilities, and violent crime in schools. Journal of police crisis negotiations, 11(2), 159-176.

May, D. C., Fessel, S. D., \& Means, S. (2004). Predictors of principals' perceptions of school resource officer effectiveness in Kentucky. American Journal of Criminal Justice, 29(1), 75-93.

McDevitt, J., \& Panniello, J. (2005). National assessment of school resource officer programs: survey of students in three large new SRO programs. Document Number 209270. US Department of Justice.

Na, C., \& Gottfredson, D. C. (2013). Police officers in schools: Effects on school crime and the processing of offending behaviors. Justice Quarterly, 30(4), 619-650.

Price, P. (2008). When is a police officer an officer of the law: The status of police officers in schools. J. Crim. L. \& Criminology, 99, 541. 
Schreck, C. J., \& Miller, J. M. (2003). Sources of fear of crime at school: What is the relative contribution of disorder, individual characteristics, and school security?. Journal of School Violence, 2(4), 57-79.

Seals, D., \& Young, J. (2003). Bullying and victimization: Prevalence and relationship to gender, grade level, ethnicity, self-esteem, and depression. Adolescence, 38(152).

Theriot, M. T. (2009). School resource officers and the criminalization of student behavior. Journal of Criminal Justice, 37(3), 280-287.

Theriot, M. T. (2016). The impact of school resource officer interaction on students' feelings about school and school police. Crime \& Delinquency, 62(4), 446-469.

Theriot, M. T., \& Orme, J. G. (2016). School resource officers and students' feelings of safety at school. Youth Violence and Juvenile Justice, 14(2), 130-146.

Tomz, M., King, G., \& Zeng, L. (2003). ReLogit: Rare events logistic regression. Journal of statistical software, 8(i02).

Weiler, S. C., \& Cray, M. (2011). Police at school: A brief history and current status of school resource officers. The Clearing House: A Journal of Educational Strategies, Issues and Ideas, 84(4), 160-163.

Young, R., \& Sweeting, H. (2004). Adolescent bullying, relationships, psychological well-being, and gender-atypical behavior: A gender diagnosticity approach. Sex roles, 50(7-8), 525537.

Zhang, G. (2019). The effects of a school policing program on crime, discipline, and disorder: A quasi-experimental evaluation. American Journal of Criminal Justice, 44(1), 45-62. 
SCHOOL POLICING IN KOREA 26

Table 1. Descriptive Statistics

\begin{tabular}{|c|c|c|c|c|c|c|}
\hline \multirow[b]{2}{*}{ Variables } & \multicolumn{3}{|c|}{ Total $(\mathrm{N}=7,109)$} & \multirow{2}{*}{$\begin{array}{c}\text { KSPOs } \\
(\mathbf{N}=\mathbf{4 , 2 3 4}) \\
\text { Mean }\end{array}$} & \multirow{2}{*}{$\begin{array}{c}\text { No KSPOs } \\
(\mathbf{N}=\mathbf{2 , 8 7 5 )} \\
\text { Mean }\end{array}$} & \multirow[b]{2}{*}{ t-value } \\
\hline & Mean (SD) & Min & Max & & & \\
\hline \multicolumn{7}{|l|}{ Dependent Variable } \\
\hline Violent Delinquency & $0.01(0.08)$ & 0 & 1 & 0.02 & 0.02 & 0.57 \\
\hline Property Delinquency & $0.01(0.07)$ & 0 & 1 & 0.01 & 0.003 & $-1.96^{*}$ \\
\hline Bullying Perpetration & $0.01(0.10)$ & 0 & 1 & 0.01 & 0.01 & -0.12 \\
\hline Violent Victimization & $0.02(0.15)$ & 0 & 1 & 0.02 & 0.03 & 0.58 \\
\hline Property Victimization & $0.11(0.32)$ & 0 & 1 & 0.11 & 0.12 & 0.42 \\
\hline Bullying Victimization & $0.03(0.18)$ & 0 & 1 & 0.03 & 0.04 & 1.42 \\
\hline $\begin{array}{l}\text { Fear of Violent } \\
\text { Victimization }\end{array}$ & $5.73(2.99)$ & 3 & 15 & 5.68 & 5.81 & 1.76 \\
\hline $\begin{array}{l}\text { Fear of Property } \\
\text { Victimization }\end{array}$ & $6.17(3.11)$ & 3 & 15 & 6.08 & 6.3 & $2.97 * *$ \\
\hline $\begin{array}{l}\text { Fear of Bullying } \\
\text { Victimization }\end{array}$ & $3.93(2.13)$ & 2 & 10 & 3.88 & 4.01 & $2.47^{*}$ \\
\hline \multicolumn{7}{|l|}{ Independent Variable } \\
\hline KSPOs & $0.6(0.49)$ & 0 & 1 & - & - & - \\
\hline \multicolumn{7}{|l|}{ Control Variable } \\
\hline Attachment to Teacher & $7.44(2.37)$ & 3 & 12 & 7.64 & 7.15 & $-8.58 * *$ \\
\hline Disorder & $5.02(1.85)$ & 3 & 12 & 4.96 & 5.11 & $3.55^{* *}$ \\
\hline $\begin{array}{l}\text { School Crime Prevention } \\
\text { Program (SCPP) }\end{array}$ & $1.83(0.51)$ & 0 & 2 & 1.96 & 1.63 & $-28.53 * *$ \\
\hline Male & $0.47(0.5)$ & 0 & 1 & .47 & .45 & -1.77 \\
\hline Age & $16.52(1.13)$ & 15 & 18 & 16.45 & 16.62 & $6.45^{* *}$ \\
\hline
\end{tabular}

Note. ${ }^{*} p<.05,{ }^{* *} p<.01$ 
SCHOOL POLICING IN KOREA 27

Table 2. Rare Events Logistic Regression of Delinquency and Victimization

\begin{tabular}{|c|c|c|c|c|c|c|c|c|c|c|c|c|}
\hline \multirow{3}{*}{ Variables } & \multicolumn{6}{|c|}{ Delinquency } & \multicolumn{6}{|c|}{ Victimization } \\
\hline & \multicolumn{2}{|c|}{ Violent } & \multicolumn{2}{|c|}{ Property } & \multicolumn{2}{|c|}{ Bullying } & \multicolumn{2}{|c|}{ Violent } & \multicolumn{2}{|c|}{ Property } & \multicolumn{2}{|c|}{ Bullying } \\
\hline & $b(\mathrm{SE})$ & OR & $b(\mathrm{SE})$ & OR & $b(\mathrm{SE})$ & OR & $b(\mathrm{SE})$ & OR & $b(\mathrm{SE})$ & OR & $b(\mathrm{SE})$ & OR \\
\hline Male & $1.54(0.34)$ & $4.65^{* * *}$ & $0.95(0.35)$ & $2.58^{* *}$ & $-0.24(0.24)$ & 0.78 & $0.52(0.16)$ & $1.68^{* *}$ & $0.13(0.08)$ & 1.14 & $-0.38(0.14)$ & $0.68 * *$ \\
\hline Age & $-0.09(0.11)$ & 0.92 & $-0.03(0.13)$ & 0.97 & $-0.38(0.10)$ & $0.69^{* * *}$ & $-0.29(0.07)$ & $0.75^{* * *}$ & $-0.03(0.03)$ & 0.97 & $-0.19(0.06)$ & $0.82 * *$ \\
\hline Disorder & $0.15(0.06)$ & $1.16^{*}$ & $0.10(0.08)$ & 1.11 & $0.14(0.06)$ & $1.15^{*}$ & $0.35(0.04)$ & $1.42 * * *$ & $0.19(0.02)$ & $1.21^{* * *}$ & $0.27(0.04)$ & $1.31^{* * *}$ \\
\hline Attachment & $-0.14(0.06)$ & $0.87^{*}$ & $-0.13(0.07)$ & 0.88 & $-0.04(0.05)$ & 0.96 & $-0.05(0.04)$ & 0.95 & $-0.04(0.02)$ & $0.96^{*}$ & $-0.03(0.03)$ & 0.97 \\
\hline Delinquency & & & & & & & $1.28(0.20)$ & $3.58^{* * *}$ & $0.97(0.17)$ & $2.65^{* * *}$ & $0.76(0.22)$ & $2.14^{* *}$ \\
\hline Victimization & $1.50(0.28)$ & $4.48^{* * *}$ & $1.62(0.34)$ & $5.07 * * *$ & $1.40(0.24)$ & $4.05^{* * *}$ & & & & & & \\
\hline SCPP & $-0.01(0.24)$ & 0.99 & $-0.30(0.29)$ & 0.74 & $-0.15(0.20)$ & 0.86 & $-0.32(0.14)$ & $0.73^{*}$ & $0.23(0.09)$ & $1.25^{* *}$ & $-0.21(0.12)$ & 0.81 \\
\hline KSPOs & $-0.12(0.30)$ & 0.89 & $0.88(0.37)$ & $2.42 *$ & $0.09(0.25)$ & 1.10 & $0.11(0.19)$ & 1.11 & $-0.06(0.08)$ & 0.94 & $-0.07(0.15)$ & 0.93 \\
\hline Constant & $-4.50(2.03)$ & $0.01 *$ & $-5.39(2.45)$ & $0.005^{*}$ & $1.15(1.62)$ & 3.16 & $-0.42(1.31)$ & 0.65 & $-2.68(0.61)$ & $0.07 * * *$ & $-0.90(1.04)$ & 0.40 \\
\hline $\begin{array}{l}\text {-2Log } \\
\text { Likelihood }\end{array}$ & \multicolumn{2}{|c|}{-290.59} & \multicolumn{2}{|c|}{-223.89} & \multicolumn{2}{|c|}{-399.01} & \multicolumn{2}{|c|}{-709.30} & \multicolumn{2}{|c|}{-2432.89} & \multicolumn{2}{|c|}{-959.43} \\
\hline
\end{tabular}

Note. ${ }^{*} p<.05 ; * * p<.01 ;{ }^{* * *} p<.001$ 
SCHOOL POLICING IN KOREA 28

Table 3. OLS Regression of Fear of Crime

\begin{tabular}{llccccc}
\hline \multirow{2}{*}{ Variables } & \multicolumn{2}{c}{ Violent } & \multicolumn{2}{c}{ Property } & \multicolumn{2}{c}{ Bullying } \\
& $b(\mathrm{SE})$ & $\mathrm{z}$ & $b(\mathrm{SE})$ & $\mathrm{z}$ & $b(\mathrm{SE})$ & $\mathrm{z}$ \\
\hline Male & $-0.90(0.07)$ & $-13.27^{* * *}$ & $-0.91(0.07)$ & $-13.12^{* * *}$ & $-0.77(0.05)$ & $-16.16^{* * *}$ \\
Age & $-0.01(0.03)$ & -0.49 & $0.08(0.03)$ & $2.60^{* *}$ & $-0.05(0.02)$ & $-2.24^{*}$ \\
Disorder & $0.47(0.02)$ & $25.3^{* * *}$ & $0.49(0.02)$ & $25.71^{* * *}$ & $0.34(0.01)$ & $26.01^{* * *}$ \\
Attachment & $0.01(0.01)$ & 0.23 & $-0.03(0.01)$ & $-2.00^{*}$ & $-0.01(0.01)$ & -0.93 \\
Victimization & $0.37(0.09)$ & $3.87^{* * *}$ & $0.83(0.10)$ & $8.49^{* * *}$ & $0.57(0.07)$ & $8.53^{* * *}$ \\
SCPP & $-0.10(0.07)$ & -1.39 & $0.01(0.07)$ & 0.19 & $-0.05(0.05)$ & -0.95 \\
KSPOs & $0.003(0.07)$ & -0.05 & $-0.10(0.07)$ & -1.29 & $-0.04(0.05)$ & -0.82 \\
Constant & $4.21(0.53)$ & $7.75^{* * *}$ & $2.95(0.55)$ & $5.39^{* * *}$ & $3.47(0.37)$ & $9.3^{* * *}$ \\
\hline F (7, 7101) & \multicolumn{2}{c}{$137.43^{* * *}$} & $159.98^{* * *}$ & $172.16^{* * *}$ \\
R-squared & $0.119(0.118)$ & $0.135(0.136)$ & $0.145(0.144)$ \\
\hline
\end{tabular}

Note. ${ }^{*} p<.05 ; * * p<.01 ; * * * p<.001$ 